excessive. Flame indicators, too, cannot be advanced seriously in 1960 as other than highly misleading instruments. One might also make a plea for the substitution of a more descriptive name than the time-honoured "Tabular Numbers" for gas volume reduction factors. After all, most numbers come from tables.

These are, however, minor criticisms. The format of the book is clear and convenient, and, with the exception of one or two poorly reproduced photographs and an illegible table on p. 74, the printing is excellent. "Hyde and Jones" is altogether a worthy successor to "Hyde and Mills" and will long form the indispensable vade-mecum of all who, whether from the official or works-control angle, are concerned with the measurement of the calorific value of gaseous fuels. Physicists unconnected with the gas industry will also find in it much of value, and if they are surprised to find that an apparently simple operation is fraught with so many pitfalls they will also find the solution to many of their gas calorimetric problems within its pages.

R. J. H. BANKS

\section{QUANTITATIVE MORPHOLOGY}

\section{Quantitative Zoology}

By George Gaylord Simpson, Anne Roe and Richard C. Lewontin. Revised edition. Pp. vii +440 . (New York : Harcourt, Brace and Company, 1960.) n.p.

HE first edition of this work was published twenty-one years ago at a time when zoologists, particularly those interested in morphology and systematics, rarely employed statistical methods. In the meantime, interest has tended to shift in many subjects from the individual to the population, with the consequence that the use of statistical methods is much more necessary. The original authors have been joined by Dr. R. C. Lewontin in producing a revised version which, while having the same general plan, is more lucid and has had some mistakes removed. A chapter on the analysis of variance has been added, and the methods given usually assume that a calculat. ing machine is available. The text is essentially a detailed explanation of those elementary statistical methods which are likely to be useful to zoologists in general and taxonomists in particular. Many examples, mostly drawn from the vertebrates, are fully worked out so that no other statistical source would be required. The least mathematical of zoologists should be able to follow the arguments and thereafter apply the methods to his own work. The biological significance of parameters or tests of significance is indicated wherever it is known. The last two chapters deal with graphic methods and with the problems of growth, respectively.

The authors admit that there are now many more good books on biometry, statistics, and general quantitative methods than when this work was first published. The most cogent argument for a new edition was that the book was still in demand though out of print. It is also true that many statistical works, so far as they touch on biology, are biased in the direction of agriculture. It seems debatable, however, whether, in view of the large number of statistical texts available, it might have been possible to reduce this side of the work and to expand it in other directions. The subject of sampling in the actual circumstances of Nature is rarely adequately discussed, and yet it raises many difficulties, though perhaps more for the ecologist. The paragraph on the capturerecapture method is perhaps too short to be useful in view of the real difficulties in interpretation and the many possible modifications of the simplest theory. Possibly the negative binomial distribution might be worth discussing; at least the bibliography might include more references to works in which additional or more refined methods are described.

The great merit of the work as it stands is its lucidity, which in this particular subject is a transcendent advantage. Nearly all taxonomists will find something useful to them in one chapter or another and very little that they cannot understand.

O. W. RICHARDS

\section{SULPHATED POLYSACCHARIDES}

\section{Polysaccharides in Biology}

Transactions of the Fourth Conference, May 21, 22, and 23, 1958. Edited by G. F. Springer. Pp. 326 . (New York: Josiah Macy, Jr. Foundation, 1959.) 5.95 dollars.

WHIS is the report of a conference held at Princeton, New Jersey, in May 1958 on the sulphated polysaccharides. There are seven chapters, each associated with a main speaker whose acount is followed by a discussion and further contributions. The chapter headings are: chondroitin sulphates (K. Meyer), biology of chondroitin sulphates (R. H. Follis), heparin and related substances (M. L. Wolfrom), the mast cell (R. D. Higginbotham), biosynthesis of sulphated polysaccharides (H. Boström), synthetic non-biological sulphated polysaccharides (M. J. Shear) and sulphated polysaccharides of plants (L. Stoloff).

The style of the book is provocative, and there will not be many neutral opinions about it. As in other Macy 'multiprofessional conferences', the proceedings are reported verbatim, with a few afterthoughts interpolated into the text. To this reviewer the presentation, reading like a playscript, has many merits, but a few 'stage directions' in the way of sub-headings would be helpful. There are no sub-headings within the chapters, and, since these are up to 60 pages long, the index assumes a vital function, but even though this is 20 pages long, in the circumstances it is barely adequate. Moreover, the lack of subdivision makes it difficult to discover when the main speaker has finished, and the contents page gives no inkling that a second speaker may also have presented a lengthy description of his own. work. In the chapter associated with Meyer's name, the main speaker in terms of continuous matter is -in fact Jeanloz. A further general disadvantage is that this is a conference of experts, and definitions which would be out of place in the conference room are necessary to the less-specialized reader. A glossary would be helpful.

An advantage that could be legitimately expected of this type of presentation is that it should be available for printing as soon as the tape-recorder has yielded its secrets to the typewriter. It is surprising to learn from the publishers that 20 months elapsed between the conference and the book becoming available in January 1960. Much that, was new at the conference has since been published elsewhere. Nevertheless, the authoritative nature of the papers and the importance of the subject 